\title{
Translating meaning as cognitive socio-cultural systems. A conceptual approach to the translation of plurilingualism in postcolonial literary discourse in Portuguese. ${ }^{1}$
}

\author{
Rebeca Hernández \\ Universidad de Salamanca
}

Recent approaches to language, meaning and cognition contend that participants in linguistic interaction construct a mental representation of their understanding of discourse on the basis of linguistic expressions, world or experiential knowledge, socially-shared beliefs, and the imagination. Focusing on the implications the coexistence of different languages has for the construction of a cognitive culture system, this paper argues that choosing monolingualism for the translation of postcolonial plurilingual texts imposes semantic limitations, which may result in a dissimilar, domesticated, representation of the recreated reality. Besides taking an ethical stand, this paper also claims that preserving the plurilingualism of these texts responds to the wish to invite readers to open new mental spaces, where the cognitive system of the translated culture can be located. The analysis of examples from the translation into English of postcolonial texts in Portuguese will show strategies to achieve this aim.

\section{Translation and the conceptualization of cultural specifics}

The widely acknowledged assumption that translation is a form of transmitting culture across languages, regardless of the communication type and the discourse genre, requires us to consider the transmission of meaning from one language to another as including contextual knowledge and culturallybound situations or practices. This is an issue which, in agreement with recent linguistic theories, takes the concept of meaning away from a narrow semantic interpretation and reframes it to incorporate cognition. In her article "Transfer of knowledge in cross-cultural discourse", Rothkegel addresses this crucial question and claims that "even if one recognizes the relevance for translation tasks of 'cultural specifics' or 'cultural differences', it is not clear exactly in what way to conceptualize them" (2000: 192). Tymoczko also puts the emphasis on the conceptualization of translators and translation in her article "Ideology and the Position of the Translator", where she thoroughly explores their conception as an "in between space", advocating that "a firm cognitive and theoretical foundation" may help to solve some of the problems encountered in current discourse on translation (2003: 181).

According to Talmy's investigations in cognitive semantics and human cognition, individuals possess a cognitive culture system, integrally 
related with the cognitive language system but not coincident with it, which is responsible for the acquisition and exercise of cultural patterns. The cognitive culture system works by exposure to social group behaviour, which Talmy sees as subdivided into distinct groups whose relevance on the modelling of cultural schematic patterns vary depending on the situation: "a family group, a gender group, a peer group, an ethnic group, a religious group, a group based on class or other social status, and a national group" (2000: 378). On similar grounds and focusing on contemporary cognitive anthropology, Lakoff claims "that most of our cultural reality resides not in the artefacts of society, but in the culture-specific schemas imposed by human beings"; he recalls that Fillmore's theory of frame semantics sees the meaning of words and grammatical expressions as "defined only relative to such schemas" and that "the need for such schemas has become generally accepted throughout the cognitive sciences" (Lakoff 1988: 135).

The same interface between language form, language meaning and conceptualization is at the basis of Fauconnier's theory of mental spaces (1994 [1985], 1997). Fauconnier describes "meaning construction" as "the high-level, complex mental operations that apply within and across domains when we think, act and communicate" and says that domains "are also mental, and they include background cognitive and conceptual models as well as locally introduced mental spaces" (1997: 1). Fauconnier considers that for every single form of language there are an array of meaning configurations, actual or potential, a variety of background frames, relevant pragmatic functions and an ample selection of possible contexts (1994: xxvii). In Fauconnier's terms, discourse configurations are "highly organized and complex within the social and cultural contexts, and the raison d'être of grammatical constructions and words within them is to provide us with (imperfect) clues as to what discourse configurations to set up" (1997: 5). Along the same line, Zelinsky-Wibbelt connects meaning with "the interpretation arising from the speaker's conceptualization of reality" (2003: 202) and notes that the fact that conceptualization differs from culture to culture acts as a conditioning factor in the translation process. She describes translation as communication between languages whose cognitive and cultural backgrounds are non-equivalent, and sees the role of the translator as that of a negotiator whose task is to approximate "the mental representations of source and target language communities" (2003: 202).

Zelinsky-Wibbelt coincides with Rothkegel in the translator's need to build a mental model of the text to compensate for deficiencies in the transmission/translation of cultural-specific information or knowledge. Rothkegel states that "the general strategy is usually to try to make explicit that which is presupposed" (2000: 190), but considers insufficient "a spontaneous understanding of the text by the translator", advocating instead "a strong move away from the perspective of reception of the source text to the perspective of production of the target text". The advantages of this change in viewpoint (from receiver/translator to translator/producer) lie in the need for producers to account for all constituents of the text, i.e. the 
linguistic, situational, communicative, and socio-cultural knowledge. Following Johnson Laird's theory of mental models, Rothkegel proposes to plan the target text bearing in mind a propositional representation of the implicit and explicit information as well as the context-dependent knowledge activated by the source text (i.e. both the cultural specific knowledge and the communicative situation are represented "in terms of predicateargument configurations", 2000: 196). The implementation of this procedure will, in her opinion, allow receivers in the target culture to build a coherent model of the translated text, thus facilitating the recovering and understanding of even those aspects of the source text which involve unshared knowledge. Zelinsky-Wibbelt also argues in favour of using a mental model of the source text as a guide in the process of translation in order to compensate for the semantic imbalance between source and target languages. However, she also discusses the adequacy of mental models to cover that information whose conceptualization involves experiential, physically based image schemas, and presents the example of spatial image schemas whose scope, frequently tied to certain concrete uses of linguistic items such as prepositions, may vary from one language to another. Zelinsky-Wibbelt coincides with Rothkegel once again on the convenience of using propositional representations to construct a mental model which includes non-equivalent linguistic, social and cultural realia and presents this practice as an effective means to translate all types of implicit knowledge (2003: 212).

However, the choice of translating unshared knowledge and sociocultural specific concepts or models by means of propositional representations becomes a central issue when the source text is plurilingual, for propositions directly concern the meaning of the sentences in the text, regardless of the language in which these sentences are written. Given the plurilingual context of creation of postcolonial literary discourse, choosing to translate meaning propositionally might actually imply creating a monolingual text in the target language. The decision of producing a monolingual translation of a plurilingual postcolonial text is not without a cost. Postcolonial criticism agrees in considering postcolonial literature as "resistance writing" and values multilingualism as one of the most efficient tools to effectively stand in opposition to the dominant culture. Said sees in postcolonial literary writing a "conscious effort to enter into the discourse of Europe and the west, to mix with it, transform it, to make it acknowledge marginalized or suppressed or forgotten histories" (Said 1993: 216), and makes it part of a general search for group identity: "from that insight came literatures, innumerable political parties [...] and, much of the time, newly independent states [...] national culture" (1993: 215). Bhabha situates hybrid linguistic manifestations resulting from the co-existence of multiple languages and distinct socio-cultural practices at the centre of the evolving position that the formerly dominated nations occupy in the world, and so he says that "in place of the polarity of a prefigurative self-generating nation itself and extrinsic Other nations, the performative introduces a temporality 
of the 'in-between' through the 'gap' or 'emptiness' of the signifier that punctuates linguistic difference" (1990: 299). Similarly, translation theorists like Venuti point at the subversive use that postcolonial writers often make of linguistic hybridity by introducing "traces of the indigenous language" in the Europhone language "through lexical and syntactical peculiarities, apart from the use of pidgins and the sheer embedding of indigenous words and phrases" (1998a: 174). And as background for postcolonial literary works, Tymoczko describes a culture which should be understood as "a language, a cognitive system, a literature [...], a material culture, a social system and legal framework, a history and so forth", calling attention to the fact that "in the case of many former colonies, there may be even more than one culture or one language that stand behind a writer's work" (1999: 20).

\section{Conceptualizing hybrid cultural systems: the case of plurilingual postcolonial societies}

Reconsidering Talmy's cognitive culture system in relation to the construction of a hybrid cultural reality, he contends that an individual simultaneously exposed to different co-existing cultural systems may develop his/her own cognitive culture system (a) by primarily adopting one pattern and excluding the other(s); (b) by developing a blend of the different cultural inputs; and (c) by assigning different psychological compartments for each pattern depending on the cultural or communicative situations (2000: 381). A good illustration of all three options is combined in the life and work of Mozambican writer Luís Bernardo Honwana whose highly praised collection of short stories, Nós Matámos o Cão-Tinhoso, a pillar of literary and political life when it was published in 1964, at a time when Mozambique was still a Portuguese country, will be used as research corpus in this paper. Honwana grew up in a Ronga and Portuguese environment as his father was an assimilado, i.e. an African who worked as an interpreter for the colonial administration, and is therefore bilingual in Portuguese and Ronga, a Bantu language. Even though Nós Matámos o Cão-Tinhoso is basically written in standard normative Portuguese, there are traits in this collection of the multicultural and plurilingual cognitive patterns identified by Talmy and representative of the society reflected in Honwana's work. For example, in his stories there are African characters who speak only Portuguese in the Portuguese context of the school (like the children in the title story: "Nós Matámos o Cão-Tinhoso"), characters who produce a blended version of Ronga or other African languages and Portuguese to communicate with any Portuguese speaker (as happens in "Dina" when Maria, a native girl, talks to the Portuguese overseer), and characters who change from one code to another depending on the interlocutor (as the mother in the story "Papa, Cobra e Eu" who speaks Portuguese with her son and Ronga with her maid although the son would have had no problem in communicating with her in Ronga). This multiple 
use of languages and language blending is a conscious and deliberate process on the part of the writer who, on the whole, defends translating into Portuguese his characters' African language to preserve their expressiveness, their psychological profile and their dignity (Honwana in Laban 1998: 675), but who does not renounce plurilingualism as a form of struggle for survival and empowerment.

In his article "Cultural Models of Linguistic Standardization", Geeaerts (2003) links cultural models with language attitudes and cognitive models, and studies the relation they hold with real actions and situations, as well as with ideology. Geeraerts says that cultural models "act as cognitive reference points" for real phenomena and are not limited to the representation of entities or situations, as they also help to sustain ideological belief systems. He characterizes models as being "abstract, general, perhaps even more simplistic" than the actual situations they stand for, and attributes this to the fact that their core cognitive function is "to make sense of the phenomena that are intrinsically more complicated" (2003: 26-27). Within this frame, Geeraerts speaks of multilingualism as characteristic of the postmodern cultural model which, in his opinion, results from the convergence of two classic linguistic and cultural models: the rationalist and the romantic models. Geeraerts argues that in the rationalist and romantic models the functional use of major standard languages and non-standard languages (varieties or dialects) is a central issue: in the rationalist model, standard languages are communicative tools "typically used in cultural, educational, scientific and political contexts" (2003: 36); in the "romantic model" the use of the minor non-standard variety works for "the expression of an identity" (2003: 38), and against the dominance of the standard language. Geeaerts presents the postmodern model as emergent and mentions certain areas of France, Germany and the African British ex-colonies as examples. We believe, in fact, that the postcolonial reality, in our case of the African nations which were former Portuguese colonies, provides a fairly developed case study of the postmodern socio-cultural model as described by Geeaerts. We also contend that the practice of translating the plurilingual and multicultural scenario depicted in the literature of these countries poses a series of problems whose solution implies a thorough examination of the whys, whats and hows of the translation process.

Now, with plurilingual postcolonial discourse in mind, the advisability of translating the specifics of one socio-cultural model into another socio-cultural model by converting implicit culturally-bound information into explicit propositional content, as Rothkegel and Zelinsky-Wibbelt propose, becomes a tricky issue with reference to the monolingual pattern which could be adopted in the target text, for monolingualism would involve eliminating those traces of meaning associated with the choice of the autochthonous language(s) (e.g. subversion, identity construction, etc.). In this sense, the old question of whether the construction of mental models is limited to propositional representation only or whether it makes use of other 
types of representation, such as imaginal representation, as Garnham (1987: 134) points out, also becomes relevant.

The binary model (rationalist vs. romantic) described by Geeraerts and the convergent model (postmodern), which, according to him, results from the evolution imposed by the dynamics of history, runs parallel to critical and analytical theories developed within the frames of postcolonialism and cognitivism respectively. For example, Bhabha's notion of "third space" draws from the concept of hybridity and maintains that "it is in the emergence of the interstices - the overlap and displacement of domains of difference- that the intersubjective and collective experience of nationness, community interest, or cultural value are negotiated" (1994: 2). Ashcroft, Griffiths and Tiffin, on their part, call attention to the fact that the binary conception of postcolonial societies is a "tendency of Western thought" to polarize the positions of the dominant and dominated and "suppress ambiguous or interstitial spaces between the opposed categories" (2000: 2325). They claim that "a simple distinction between centre/margin; colonizer/colonized; metropolis/empire; civilized/primitive represents very efficiently the violent hierarchy on which imperialism is based and which it actively perpetuates" (2000: 24). Bhabha proposes conceptualizing the inbetween space of postcoloniality not as "an alien territory" but as "an international culture, based not on the exoticism of multiculturalism or the diversity of cultures but on the inscription and articulation of culture's hybridity." (1994: 38, his italics). The conceptualization of postcolonial societies in general, and postcolonial literary discourse in particular, in terms of hybridity is thus crucial to identify and interpret the real meaning of plurilingualism in a type of discourse which uses linguistic alternation and linguistic merging to reflect the tensions and negotiations between co-existing asymmetric cultures.

\section{Translating plurilingual hybridity as conceptual integration: exam- ples from Portuguese postcolonial literature and its translation into English}

From a cognitive perspective, postcolonial hybridity can be analyzed as a case of blending or conceptual integration. Fauconnier and Turner (1994, 2001, 2002) define blending as "a general instrument of cognition", and place it at the centre of a series of general cognitive operations (such as framing, analogy, metaphor, grammar, narration or commonsense reasoning), which they see as essential for the construction of meaning. For them, blending "is prerequisite" to all these phenomena, and is in no way "restricted to phenomena of language" (1994: 4-5). For Fauconnier and Turner, blends have the capacity "to represent, mentally, a new reality, in culture, action and science" (2002: 21), and it is in this sense that blending may be helpful in explaining how postcolonial hybridity actually emerges as a result of the intertwined network of socio-cultural and linguistic frames 
and relations which lies at its basis. Thinking of hybridity in terms of blending offers a model for conceptualization and analysis relevant to the need expressed by Rothkegel (2000: 192), in the quote above. It also helps to view the hidden meaning underlying plurilingual discourse as connected to experience, action, negotiation, world and identity construction, a host of interrelated issues, which in the long run prove central to a theory of postcolonial translation. This is what happens, for example, in the following passage taken from Honwana's short story "Papa, Cobra e Eu" where a prayer in the national language is inserted in the middle of the discourse in Portuguese, helping to strengthen and define the characters' sense of identity.

(1) Quando a Sartina acabou de tirar os pratos e arrumou a toalha o Papá começou:

Tatana, ha ku dumba Hosi ya tilo ni misaba...

Quando acabou estava de olhos vermelhos. (1972: 104)

[When Sartina finished clearing away the plates and folded the cloth, Papa began: "We trust you, Father, Lord of Heaven and Earth"

When he finished, his eyes were red]

Fauconnier and Turner's conceptual integration model, of which blending is a basic cognitive tool, "is concerned with on-line, dynamical cognitive work people do to construct meaning for local purposes of thought and action" (2001:7). To explore its role in cognitive, communicative and experiential processes, it requires thinking of language as "a superficial manifestation of hidden, highly abstract, cognitive constructions" (Fauconnier 1997: 34), and it also entails thinking of humans' mental representations of discourse in terms of mental spaces. In Fauconnier's words, "mental spaces are the domains that discourse builds up to provide a cognitive substrate for reasoning and for interfacing with the world" (1997: 34); thus, the analysis of mental spaces and the analysis of the transfers of meaning between ample domains of general knowledge, or between the more specific partial structures of knowledge which concrete mental spaces represent, offer a means to systematize the type of cognitive activity which connects discourse with knowledge and understanding processes, as well as with specific portions of reality.

Though mental spaces are set up locally as information comes along, a configuration of interrelated mental spaces often initiates multiple projections of conceptual material in a way which is essential for the construction of complex meaning paradigms, as well as for the understanding of discourse and socio-cultural schemas, which provide the conventional inner structure for the organization and interpretation of experience. For example, in a cognitive cultural system which results from the blending of disparate languages and patterns of behaviour, such as that corresponding to plurilingual postcolonial societies, a conscious unfolding of the cognitive opera- 
tions underlying the process of integrating conceptual structures from various socio-cultural sources requires the building of separate mental spaces, one at least for each of the co-occurring languages, cultures, traditions, experiences, or practices. These mental spaces should be seen as inputs working inter-connectedly for the construction of a densely integrated conceptual whole (the hybrid third space defined by postcolonial theoreticians, cf. Bhabha 1994), which is linked to them in systematic ways, but develops its own emergent cognitive structure (Fauconnier and Turner 2001: 2).

In that sense, any piece of postcolonial plurilingual literary discourse (in our case in Portuguese) may be conceptualized as a blended mental space which derives its structure and meaning from the autochthonous and colonial socio-cultural legacies (narrative, literary, linguistic and otherwise) serving as inputs. Just like any other blended space, postcolonial literary discourse combines characteristics inherited from the inputs, but it may include new structures not projected from them which could be associated with processes of identity construction. As a new hybrid reality, postcolonial literature is capable of recreation, elaboration, and interaction with the source systems whose traditions it follows but on which it can also have an influence.

This large-scale input-blending design also works at phrase and utterance levels, which is basically the translator's down-to-earth level of work. Thus, when faced with a text which shows signs of a plurilingual and multicultural reality, such as those cases of code-switching found in the following quote from Honwana's short story "Dina" (included in the collection Nós Matámos o Cão-Tinhoso), there will be the need for the translator to consider whether a monolingual translation may or may not fail to convey that sort of meaning built on socio-cultural connotations and contextual effects, which the author implicitly activates by the (no matter how slight) use he makes of plurilingualism:

(2) O grupo da horta devia ter tardado, porque José, o seu kuka, ainda estava a fazer a fogueira para a botwa de farinha. (1972: 62)

[The Farm Gang must have been delayed, because their cook, José, was still making their fire for their pot of cornmeal.]

A cognitive analysis aimed at helping in the decisions which will be taken with regard to the translation of this sentence involves evaluating the significance of the interaction holding between the two mental spaces created for the languages of the text: the Portuguese in which it is written and the national languages present in the African words kuka and botwa, which pertain to the Mozambican context and provide by default the cultural background of the story. On ethical grounds, postcolonial and translation theoreticians (cf. for example, Spivak 1993, 1995; Venuti 1995; Vidal 1998; Bandia 2001; Santos 2005) would argue against domesticating 
translation by homogenizing the language of a plurilingual text like this one as a way to preserve the autochthonous cultural values and to create conditions for equal dialogue between the source and target languages. The same claim may be made if cognitive theory is taken as basis for the analysis.

When we think of the substratum of pragmatic authorial decisions which may underlie the plurilingualism of this text, there are a number of reasons to be considered. For example, the choice of Portuguese can be explained by the need to pursue a wider audience or by the need to accommodate a written literary text to the classic written status of Portuguese literature over the oral tradition of most African literature. But the real fact is that the writer's choice to integrate African expressions into his discourse in Portuguese with no translation, no graphic marks, and no explanation or adaptation of their meaning has the direct effect of recreating for the reader, at a purely cognitive level, the integrated socio-cultural background which is a component of the story. On an equal basis, the reader has the opportunity to conceptualize the plurilingual signs of the information received as part of an integrated whole and consequently may build a mental model which includes the merging of languages, cultures and contexts. The relevance of this wide-scope meaning construction seems to override the need to ensure assigning meaning at the micro level of words and expressions.

The same aim is achieved by Guedes when she translates this sentence as part of her translation of Honwana's book into English, published in 1969 under the title We Killed Mangy-Dog and Other Mozambican Stories. There, she maintains the Mozambican words, but marks them with an asterisk and explains them at the end of the story (here, below the quotation):

(3) The Farm Gang must have been delayed, because their ku$\mathrm{ka}^{*}$ * José, was still making their fire for their botwa* of cornmeal. (1987: 6)

kuka: adaptation of cook

botwa: three-legged iron pot

The cognitive result for the reader of this translation is an on-line activation of an African reality, regardless of the fact that the main language is English. Thus, the effect of a hybrid plurilingual world obtained by the author through the strategy of introducing autochthonous words in his discourse in Portuguese is maintained in the translation. This effect would have been lost, or at least lessened, if the propositional representation of their culturally-bound content had been chosen instead:

(4) The Farm Gang must have been delayed, because their cook, José, was still making their fire for their three-legged iron pot of cornmeal. 
In fact, the only trace of a non-English world in (4) would be the personal name "José" (which also provides reasons for the practice of leaving proper names untranslated). When the African words are kept as in (3), and even if their meaning, unknown to the reader, may open a momentaneous silent gap in his/her understanding and interpretation process, the phonological and lexical structure of these words have the capacity to activate a cognitive model which accommodates the cultural patterns underlying the represented reality (the African and the Europhone) by the blending of two inputs (the autochthonous language and the colonizer's) (Talmy 2000: 381). This local case of blending may serve to illustrate the highly complex and well established conceptual integration network which lies beneath the postcolonial socio-cultural system. In agreement with the authors cited above (Bhabha 1994; Ashcroft, Griffiths and Tiffin 2000; Geeraerts 2003), who postulated in some way or other the autonomy of the hybrid or blended reality from both the national and the acquired colonizing cultures, the conceptual blend, of which the case considered so far is just a minimum example, gives rise, as Fauconnier and Turner specify, to "a particular process of meaning construction" which draws from both sources but ends up creating its own cognitive configuration, with its own "inferences, emotions and event-integrations". The new meaning "cannot reside in any of the inputs; they have been constructed dynamically in a new mental space, the blended space", which, however, remains connected to the inputs in a systematic and coherent way (2001: 2).

Other strategies for integrating languages and cultures in postcolonial literary discourse in Portuguese make use of more complex plurilingualized communicative techniques, which are also representative of the linguistic spectrum of the African-Portuguese community. We may illustrate this with examples from the same short story collection by Honwana. For instance, the following fragment in "Nhinguitimo" shows a case of language integration in one of the communicative exchanges the African protagonist has with a Portuguese-speaking character; it combines codeswitching, through the introduction of the Swazi expression bayeti n'kossi into the Portuguese discourse, and a phonological and syntactic reproduction of a pidginized oral version of African-Portuguese:

$$
\begin{aligned}
& \text { (5) -Vírgula Oito! -chamou o Rodrigues [...] } \\
& \text {-Bayeti n'kossi! } \\
& \text {-Como é que tu te chamas, ó rapaz? perguntou o adminis- } \\
& \text { trador. } \\
& \text {-Eu chama Alexandre Vírgula Ôto Massinga, sinhoro Mix- } \\
& \text { adoro! (1972: 126-127) }
\end{aligned}
$$

The fusion of languages (Swazi and Portuguese) and language varieties (normative Portuguese for the Portuguese characters and the narrator, and pidginized grammatically and phonologically simplified Portuguese for the African protagonist; plus differences in the graphic representation of the 
protagonist's name: Oito [when said by Rodrigues], Ôto [when pronounced by the protagonist himself]) signal the existence of an integrated society. And once again, the socio-political and cultural blended meaning is constructed through the use of plurilingualism, which helps to conceptualize the distance between speakers, the dramatic reduction of the protagonist's social and communicative skills in the colonizer's context, and the hybridity of their linguistic interaction.

Guedes' translation of this fragment uses similar techniques to those found in the original (the explaining footnote which corresponds to the asterisk is again given below):

(6) 'Virgula Oito!' called Rodrigues [...]

'Bayeti n' Kossi'*

'Hey, boy, what's your name?' asked the administrator.

'My name Alexandre Virgula Oito Massinga, Sinhore Mishadoro'. (1987: 62-62)

* greetings, Lord!

In the translation, the spelling of the protagonist's name is unified and simplified, and initial capital letter is used for the formal Sinhore; but the expression in Swazi is kept, and the effect produced in the original by the protagonist's pidginized Portuguese when he addresses the administrator is maintained by the alteration of syntax and phonetics in the target language. Furthermore, in order to stress the specificity of the integration of languages, Guedes decides to produce an English-oriented phonic version of the African-Portuguese sinhoro Mixadoro, and so it becomes the untranslated Sinhore Mishadoro. This is a highly efficient strategy for the translation of pidginized oral language, as it approximates the target language to the source language and encourages the construction of a mental model for the target text on grounds which seek to bear a marked resemblance with those used for the original text.

To evaluate the depth of the decisions taken by Guedes, we may attempt once more to remove all traces of hybridity by turning the excerpt into a homogenizing monolingual translation in standard English:

(7) 'Virgula Oito!' called Rodrigues [...]

'Greetings, Lord!'

'Hey, boy, what's your name?' asked the administrator.

'My name is Alexandre Virgula Oito Massinga, Mr. Administrator'.

As in (4), the only vestige of a foreign culture in (7) would be the names: Rodrigues and Alexandre Virgula Oito Massinga, and the reader of the translated text would be offered fewer clues to construct a mental model which included socio-cultural and linguistic integration. A compromise strategy, also found in postcolonial texts and in their translations, would be to combine the pluriligualism of the original with the propositional meaning 
of the African expressions, which is the proposal in a possible alternative version of examples (3) and (4):

(8) The Farm Gang must have been delayed, because their kuka or cook, José, was still making their fire for their botwa, a three legged iron pot of cornmeal.

Guedes practices this technique to a certain extent in the following passage from the title story "Nós Matámos O Cão-Tinhoso", when the construction of meaning involves the recreation of a culture-specific image, that of the Mozambican lizard gala-gala. This is the original:

(9) O Cão-Tinhoso tinha a pele velha $[\ldots]$ e cheia de rugas como a pele de um gala-gala. (1972: 12)

In order to guide the reader in the construction of a similar mental image which can not be imagined or recovered from the immediate verbal context, Guedes decides to use the juxtaposition of languages to assign meaning to the concept and translates as follows:

(10)Mangy-dog skin was old [...] the skin was black and wrinkled like the skin of a Gala-gala lizard. (1987: 79)

In this case, as in all the cases discussed above, opting for (propositional) monolingual translation exclusively would have made it more difficult and less effective to achieve the goal of translating the conceptual, linguistic and culture systems associated with plurilingualism. A monolingual translation of (9) would produce a culturally unmarked image:

(11)Mangy-dog skin was old [...] the skin was black and wrinkled like the skin of a lizard.

\section{Conclusion}

The general result derived from the strategies analyzed in Guedes' work is that, even though a translation into English is actually produced, the Portuguese mental space and the African mental space are both kept active in the discourse in English, helping to build a blended space for the mental representation of the meaning conveyed. This blended space integrates conceptual structures from the African and the Portuguese socio-cultural contexts (which function as inputs 1 and 2 in this or the opposite order); it facilitates the shaping of an identity, the emergence of new context-related meaning, and the drawing of inferences; the existence of this blended space in the translation also works against domestication and in favour of the development and transmission of a cognitive culture-specific system adequate for the postcolonial reality represented in the original. 


\section{Bibliography}

\section{Primary Texts}

Honwana, Luís Bernardo (1964/1972). Nós Matámos o Cão-Tinhoso. Porto: Afrontamento.

Honwana, Luís Bernardo (1969/1987). We Killed Mangy-Dog and Other Mozambican Stories. (Trans. Dorothy Guedes) Harare: Zimbabwe Publishing House.

\section{Secondary Texts}

Ashcroft, Bill, Gareth Griffiths \& Helen Tiffin (2000). Post-Colonial Studies: The Key Concepts. London: Routledge.

Bandia, Paul (2001). "Le concept bermanien de 1' 'Etranger' dans le prisme de la traduction postcoloniale". TTR vol. 14 (2), 123-139.

Bhabha, Homi K. (1990). "DissemiNation: time, narrative, and the margins of the modern nation" H. K.Bhabha (ed.) Nation and Narration. London: Routledge, 291-322.

Bhabha, Homi K. (1994). The Location of Culture. London: Routledge.

Fauconnier, Gilles (1994 [1985]). Mental Spaces. Cambridge: Cambridge University Press.

Fauconnier, Gilles (1997). Mappings in Thought and Language. Cambridge: Cambridge University Press.

Fauconnier, Gilles and Mark Turner (1994). "Conceptual Projection and Middle Spaces"”. USCD: Department of Cognitive Science Technical Report 9401. Online at http://www.cogsci.ucsd.edu (consulted 05.02.2008)

Fauconnier, Gilles and M. Turner (1998/2001). "Conceptual Integration Networks". [Expanded web version, 10 February 2001. Online at http://markturner.org/cin.web/cin.html (consulted 05.02.2008)

Fauconnier, Gilles and Mark Turner (2002). The Way We Think. Conceptual Blending and the Mind's Hidden Complexities. New York: Basic Books.

Garnham, Alan (1987). Mental Models as Representations of Discourse and Text. New York: John Wiley \& Sons.

Geeraerts, Dirk (2003). "Cultural Models of Linguistic Standardization.” R. Dirven, R. Frank \& M. Pütz (eds). Cognitive Models of Language and Thought. Ideology, Metaphors and Meanings. Berlin: Mouton de Gruyter, 25-68.

Laban, Michel (1998). Moçambique. Encontro com escritores. vol 2. Porto: Fundação Eng. António de Almeida.

Lakoff, George (1988). “Cognitive Semantics.” U. Eco, M. Santambrogio and P. Violi (eds). Meaning and Mental Representations. Bloomington: Indiana University Press, 119-154.

Rothkegel, Annely (2000). "Transfer of knowledge in cross-cultural discourse." L. Lundquist and R. J. Jarvella (eds). Language, Text and Knowledge. Mental Models of Expert Communication. Berlin: Mouton de Gruyter, 189-206.

Said, Edward W. (1993). Culture and Imperialism. New York: Vintage Books.

Santos, Boaventura de Sousa (2005). "O futuro do FSM: o trabalho da tradução". Democracia Viva 25, Jan/Fev 2005, 28-39.

Spivak, Gayatri Chakravorty (1993). Outside in the Teaching Machine. London: Routledge.

Spivak, Gayatri Chakravorty (1995). "Translator's preface" and "Translator's note". M. Devi (ed.). Imaginary Maps. London: Routledge, xxiii-xxxi.

Talmy, Leonard (2000). Toward a Cognitive Semantics. Typology and Process in Concept Structuring. Volume II. Cambridge, Mass.: The M.I.T. Press.

Tymoczko, Maria (1999). "Post-colonial writing and literary translation". S. Bassnett \& H. Trivedi (eds). Post-Colonial Translation. Theory and Practice. London: Routledge, 19-40.

Tymoczko, Maria (2003). "Ideology and the Position of the translator. In What Sense is a Translator 'In Between'?'. M. Calzada (ed.). Apropos of Ideology. Manchester: St. Jerome. 181-201.

Venuti, Lawrence (1995). The Translator's Invisibility. London and New York: Routledge.

Venuti, Lawrence (1998). The Scandals of Translation: Towards an ethics of difference. London: Routledge.

Vidal, M. ${ }^{\mathrm{a}}$ del Carmen África (1998). El futuro de la traducción. Valencia: Institució Alfons el Magnánim. 
Zelinsky-Wibbelt, Cornelia (2003) "Integrating translation theory and translation practice." C. Zelinsky-Wibbelt (ed.). Text, Context, Concepts. Berlin: Mouton de Gruyter. 199-220.

${ }^{1}$ Financial support for this research has been provided by the Junta de Castilla y León, grant SA082A07. 